\title{
Las comedias húngaras de Lope de Vega: una cadena de intertextualidad y reescritura*
}

\author{
Adrián J. SÁEZ \\ Université de Neuchâtel \\ adrian.saez@unine.ch
}

\begin{abstract}
RESUMEN
Dentro del conjunto de comedias dedicadas a la historia de Hungría, Lope de Vega cuenta con tres comedias con numerosas similitudes: El príncipe melancólico, El cuerdo loco y La sortija del olvido. Este trabajo examina las relaciones de intertextualidad y reescritura en las tres obras, así como algunos aspectos del desarrollo de la comedia palatina lopesca.

Palabras clave: Lope de Vega; reescritura; El príncipe melancólico; El cuerdo loco; La sortija del olvido.
\end{abstract}

\begin{abstract}
In between the group of plays about the Hungarian history, Lope de Vega has three comedies with some similarities: The Melancholic Prince, The Sane Insane and The Ring of Oblivion. This work aims to examine the relationships of intertextuality and rewriting between the three plays, and also some characteristics of the development of Lope de Vega's palatial comedy.
\end{abstract}

Key words: Lope de Vega; rewriting, The Melancholic Prince, The Sane Insane; The Ring of Oblivion.

SUMARIO : 1. En torno al ciclo húngaro de Lope de Vega ; 2. Una red de comedias : intertextualidad y reescritura ; 3 . Final.

* Una primera versión titulada «Intrigas en la corte de Buda: disimulación, género y reescritura en El cuerdo loco de Lope de Vega» fue presentada en el Congreso Internacional «Las naciones europeas en la literatura del Siglo de Oro», coorganizado por la Universidad Eötvös Loránd y el GRISO de la Universidad de Navarra con la colaboración del Museo de Bellas Artes de Budapest (Budapest, 15-16 noviembre de 2013). Agradezco a László Scholz (Universidad Eötvös Loránd) tanto su amable invitación como su calurosa acogida. Del mismo modo, deriva del trabajo de edición de El cuerdo loco para Prolope (Sánchez Jiménez y Sáez, en prensa). 
Dentro del sistema dramático de Lope se encuentra un manojo de comedias situadas en la corte de Hungría - lugar este fijado con mayor o menor precisión-, diseminadas a lo largo de toda su producción dramática, en una horquilla temporal que abarca desde 1588 hasta 1623, respectivamente fechas ante quem de El príncipe melancólico y de la firma de La corona de Hungría ${ }^{1}$. Este abanico de comedias magiares (La obediencia laureada y primer Carlos de Hungría, El rey sin reino, etc.) prueban el interés de Lope por dramatizar historias ambientadas en un territorio que se entendía al mismo tiempo como lejano (geográficamente) y cercano (desde una perspectiva histórica e ideológica) ${ }^{2}$. En efecto, esta suerte de pasión húngara hunde sus raíces en causas políticas y religiosas: Gómez explica que las añejas relaciones dinásticas entre la casa de Austria y el reino húngaro constituyen la clave de la elección de Hungría como espacio, con el trasfondo de las relaciones entre las dos ramas de los Habsburgo en el turbulento marco de la guerra de los Treinta Años ${ }^{3}$.

Estas son algunas de las asociaciones que podría despertar el nombre de Hungría en el título de las comedias, amén de actuar como «reclamo publicitario» ${ }^{4}$. En esta ocasión, recuerdo a vuelapluma algunos de los rasgos esenciales de las comedias húngaras de Lope para pasar después al examen de tres piezas construidas a partir de variaciones sobre un mismo esquema dramático, esto es, unidas por relaciones de intertextualidad y reescritura.

\section{En torno al ciclo húngaro de Lope}

Lope se jacta, como tantas otras veces, de ser el primero: "Yo fui primero inventor / de la comedia en Hungría» (El animal de Hungría, vv. 328-329; Parte IX, 1617). Se trata de una orgullosa afirmación de la primacía del poeta en la conformación de un nuevo sistema dramático en España a partir de la atmósfera húngara pero que, a la vez, no deja de invitar — con una pequeña licencia— - leerse igualmente como una reivindicación de sus comedias magiares, aunque ya Guillén de Castro había visitado estas tierras en El amor constante (1596-1599; Primera parte, 1618). En verdad, en los dos sentidos Lope quiere asentar que ha dado con la

\footnotetext{
${ }^{1}$ Las referencias proceden de las ediciones consultadas o, en su defecto, de la cronología de Morley y Bruerton (1968).

2 Sobre estos textos y la ambientación en el país magiar como recurso literario, ver Tyler (1963 y 1972), pp. 23-25 y 34; Bocsi (1967 y 1975) (sendos resúmenes de Hungría en el teatro de Lope de Vega, su tesis doctoral inédita); Korpás (1999); del Río Parra (2003); Usandizaga (2005); y Gómez (2011), que comentaré infra.

${ }^{3}$ Gómez (2013), p. 80. Ver el repaso de Korpás (1999), pp. 119-123.

${ }^{4}$ Argente del Castillo (2001), p. 84; añade: «el dramaturgo contaba [...] con que su público tenía una imagen previa por la que se podía sentir interesado».
} 
tecla adecuada, ya que «las que primero había eran sin gracia y primor» (v. 330).

Sea como fuere, Hungría se convierte en uno de los espacios fabulosos preferidos en la dramaturgia áurea, y es Lope —ahora sí- quien parece escoger con más frecuencia esta imaginaria ambientación espacial, al punto que llega a conformar una suerte de ciclo de comedias húngaras que, amén de su valor dramático, revisten un cierto interés imagológico porque no abundan las noticias ni opiniones sobre Hungría o sus habitantes en otros géneros y textos coetáneos ${ }^{5}$.

En su revisión de las comedias que Mira de Amescua dedica al asunto húngaro, Argente del Castillo indica que se trata de un «género» sin otras «señas de identidad» que el uso del topónimo para designar «un espacio caracterizado de la misma forma $[. .$.$] convencional que cualquier otro de los países utilizados en$ comedias palatinas o de enredo, [...] para vincular a algún personaje a una historia, captada más como leyenda y fantasía que como evocación de un espacio cercano, conocido y problemático ${ }^{6}$. No lo creo así: antes bien, considero que las comedias húngaras comparten una serie de rasgos comunes que descubren el matiz propio que Lope concede a la ambientación en Hungría y, en el caso que se verá más adelante, el empleo repetido de un esquema dramático por parte de Lope.

Dos son los elementos fundamentales de estas piezas: el reino magiar como sede o tema de la acción y el género palatino al que pertenecen. Ciertamente, en ellas la imaginación asume el poder para configurar un mundo autónomo y quasifantástico, ordenado por normas poéticas más que por fidelidad a los detalles verídicos. De hecho, Lope hace que Hungría se convierta en un espacio idóneo para el desarrollo de conflictos dentro de la comedia palatina, un género caracterizado por el alejamiento del hic et nunc en el que casa bien que las referencias precisas sean solo un ornamento que perfile la acción según los designios del poeta, que debía de tener noticia de ciertos eventos que llegaron hasta el público hispano, como se desprende de las relaciones de sucesos de la época. Entre ellos, a buen seguro despertaría un marcado interés la «larga guerra» de Hungría (1593-1606) que volvía a enfrentar a las fuerzas imperiales y otomanas en tierras balcánicas en una contienda protagonizada por el controvertido príncipe Segismundo Bathory de Transilvania ${ }^{7}$.

La amplitud del marco cronológico y espacial de estas comedias prueba la fuerza de la invención: la corte de Buda en El cuerdo loco (aquí como capital de Albania) y El rey sin reino, Belgrado (Alba Bulgarica, entonces parte de Hungría) en La

${ }^{5}$ Así, no aparecen entre los tipos nacionales que comenta Herrero García (1966). Bocsi (1967 y 1975) ya se refiere a la «comedia de Hungría» de Lope. Weber de Kurlat (1977), p. 870, recuerda «el prestigio de ciertas naciones o ciudades» como «otro modo de fomentar el ilusionismo, la evasión en el plano imaginativo, ingrediente importante de la psicología del hombre barroco». Al respecto, ver Oleza (1997), p. 236.

${ }^{6}$ Argente del Castillo (2001), p. 83.

${ }^{7}$ Ver González Cuerva (2006), pp. 285-295. 
ventura sin buscarla, la imprecisa frontera con el imperio otomano en Los mártires de Madrid (jornadas segunda y tercera) o la ambigua Hungría de La sortija del olvido, etc. ${ }^{8}$ La libertad se impone igualmente en el tratamiento de la materia húngara, desde los dramas históricos que tienen como asunto un tema tomado de la historia magiar, poetizado de acuerdo a criterios de verosimilitud y no de realidad ${ }^{9}$, y las más frecuentes comedias ficticias («fantasiosas» para Usandizaga) que sacan a las tablas personajes de origen húngaro o presentan los hechos en ese marco centroeuropeo $^{10}$.

Esta falta de marcas temporales precisas es una clave para deslindar entre el género de la comedia palatina y «las comedias con ambientación histórica: tragedias y tragicomedias, con las cuales, no obstante, comparte la dramatización de los conflictos de poder que enfrentan a personajes pertenecientes a la alta nobleza e incluso a la realeza» ${ }^{11}$. Ahora, pese a que Lope no se detuviera en la recreación histórica, Hungría y sus problemas constituían una verdadera mina para la configuración de lances de gran fuerza dramática. Gutiérrez Gil apunta con tino que «Hungría evoca en el siglo XVII conflicto, violencia, conjuras... y es este el sello que distingue, en cierta manera, estas comedias palatinas de tema húngaro» ${ }^{12}$. Justamente, una de las claves principales de este conjunto de comedias es la preferencia por el universo del poder y la política, que se puede contemplar con mayor libertad desde esta alejada atalaya. Así se ve por ejemplo en La corona de Hungría, donde para Gómez el trasfondo histórico es un telón de fondo general en que reflexionar libremente sobre la sucesión dinástica al trono húngaro y la posibilidad de un gobierno conjunto entre dos monarcas ${ }^{13}$.

Valga este mínimo bagaje como prolegómeno antes de pasar al examen de rasgos puramente internos de la arquitectura dramática de esta gavilla de comedias. Más en detalle, en lo que sigue examino la cadena intertextual que enlaza tres de

8 Para Argente del Castillo (2001), p. 84, esta mínima concreción espacial se relaciona con la escasa definición de Hungría «desde el punto de vista geográfico, ya que su historia interna y externa lo mantiene en un proceso de cambio constante y así las fronteras se expanden y retraen en los textos sin ningún problema».

${ }^{9}$ Para el tratamiento de la historia en la época, ver solo Oleza (2013); y Usandizaga (2014).

${ }^{10}$ Esta es la clasificación que propone Korpás (1999), pp. 123-124, para una veintena larga de comedias húngaras de Lope, cuyos títulos no detalla. Coincide en líneas generales con Usandizaga (2005), p. 298. Anteriormente, ya Bocsi (1967), p. 97, n. 1, apuntaba que estas comedias de asunto húngaro carecen de fondo histórico: «son más bien resultado de la fecunda imaginación del dramaturgo, que las sitúa en Hungría sólo por capricho, o por la popularida de los acontecimientos húngaros entre su público».

${ }^{11}$ Gómez (2011), p. 1955.

${ }^{12}$ Gutiérrez Gil (2013), p. 220. Ya Argente del Castillo (2001), p. 83, subraya la importancia de Hungría en el imaginario español.

${ }^{13}$ Gómez (2011), pp. 1951-1952. 
estas comedias húngaras merced a la reescritura de Lope de una serie de motivos y paradigmas. Mis reflexiones se estructuran en torno a El cuerdo loco, comedia que ha originado este trabajo y sobre la que ya Montesinos advertía que presenta «situaciones, caracteres, tipos ya creados», de modo que se debe estudiar «en función de otras muchas comedias en que se desarrollan o se esbozan motivos análogos», porque «[c]omo pocas [...] enseña la manera de componer del poeta» ${ }^{14}$.

\section{Una red de comedias: intertextualidad y reescritura}

Sin duda, el mecanismo de la reescritura resulta esencial en la vorágine de comedias de la época, pues contribuía a saciar la constante demanda de novedades para el público, favorecía el desarrollo de una propuesta dramática y se entrecruzaba - al menos en ocasiones - con cuestiones de competencia o emulación de modelos. Lope, como primer paladín de su fórmula dramática, cultivaba este fenómeno tanto en sus composiciones dramáticas como poéticas, aunque su caso - ante todo en su vertiente dramática - todavía merece mayores indagaciones ${ }^{15}$.

Para esta ocasión, entiendo el concepto de reescritura como una suerte de intertextualidad profunda que enlaza diferentes comedias entre sí, y no como la revisión de un dramaturgo - u otro agente - de un texto propio o ajeno para dar lugar a una comedia con dos versiones, con los derivados problemas ecdóticos. En cambio, interesa reconstruir la cadena de intertextualidad y reescritura que une los textos como fórmula para su comprensión, en la estela de Antonucci ${ }^{16}$ : más allá de un mero rastreo erudito, esta perspectiva comparativa permite entender tanto la novedad como el sentido de un rompecabezas armado parcial o totalmente con piezas anteriores.

Es el caso de El cuerdo loco de Lope, que no solamente toma datos de crónicas sobre Hungría (Antonio Bonifini, Rerum hungaricarum decades, 1497; o Johannes Thurókzy, Chronica Hungarorum, 1488) sino que recupera esquemas dramáticos que ya había probado en El príncipe melancólico (1588-1595, conservada en un manuscrito apógrafo) y que retomará — parcialmente- luego en La sortija del olvido (1610-1615; Parte XII, 1619) ${ }^{17}$. En otras palabras: estas comedias palatinas

\footnotetext{
${ }^{14}$ Montesinos (1922), pp. 149-151.

${ }^{15}$ Ver Wardropper (1990); Micó (1998); Pedraza Jiménez (1998), que diferencia —más centrado en poesía - autocitas, citas ajenas, traducciones, fórmulas poéticas, diversos tipos de reescrituras creativas, etc. Fernández Mosquera (2010), expone las estrategias reescritoras de Lope en contraste con las asumidas por Cervantes, Quevedo y Calderón. Más cercano a mi aproximación se encuentran Rennert (1918); Tyler (1963). Para cuestiones teóricas sobre intertextualidad y reescritura, ver Sáez (2013b), con las referencias allí comentadas.

${ }^{16}$ Ver por ejemplo Antonucci (2013).

${ }^{17}$ Un caso parejo se da entre Los pleitos de Ingalaterra y La corona de Hungría, según
} 
conforman una tríada diseñada sobre un mismo patrón dramático y centrada en conflictos y reflexiones similares. Según se verá, seguir los pasos de este proceso contribuye a entender las pautas de la reescritura lopesca y su desarrollo del género palatino.

La crítica ya ha hermanado El cuerdo loco y La sortija del olvido: García-Varela apuntaba al paso que los conspiradores de las dos comedias quieren alejar del poder al legítimo gobernante; tras este breve apunte, López Martínez detalla algunas de las concomitancias de escenas y motivos entre los dos textos - que aprovecharé infra-, para concluir acertadamente que «esta conexión directa, y consciente» constituye «un caso de recuperación de situaciones dramáticas, o de planteamientos argumentales básicos, antes que de una reelaboración completa» ${ }^{18}$.

No obstante, siempre conviene empezar por el principio y la tentativa inicial es El príncipe melancólico, en la que Lope visita por primera vez Hungría. La comedia principia con fuerza, justo en el momento en que el príncipe del reino húngaro (sin nombre propio) reta a duelo a su hermano, el infante Leonido, por los amores de la duquesa Rosilena. En esta competencia fraterna, el príncipe dice ser preferido por la dama cuando esta, en realidad, únicamente admite el galanteo de Leonido, pero no admite su derrota hasta que la propia Rosilena le desengaña (pp. 276-278). Enterado de este lance, aparece el rey para recriminar la actitud de sus hijos: a Leonido, por no respetar a su señor natural (p. 279), y al príncipe por no saber controlarse («i $[\ldots]$ a vos no os conserváis!», p. 281). En su respuesta el infante desvela sus ambiciones políticas de gobernar («también yo he de mandar reino, / aunque no el suyo [de su hermano] de Hungría», p. 280), sumando un enfrentamiento dinástico al conflicto amoroso.

Para apagar este fuego que amenaza con extenderse, el rey resuelve enviar al infante a Polonia para que, a la vez de servirle como castigo, pueda aprovechar su ausencia para «domar» al príncipe (p. 282), pero el descubrimiento de la verdad (de boca del conde Marcelo, pp. 282-283) hace que revoque su decisión y decida hacer justicia $^{19}$. Mientras tanto, el príncipe ha vuelto a rondar a Rosilena, contra la orden de su padre, y amenaza con matar a su hermano («Si yo le diera muerte / al infante, mi enemigo, / yo sé que blanda estuvieras / y que me favorecieras / y estuvieras

estudian Rennert (1918); Tyler (1963 y 1972), pp. 23-25 y 34; Bocsi (1967), pp. 99-102; Gómez (2011), pp. 1957-1963.

${ }^{18}$ García-Varela (1993), p. 198; López Martínez (2010), pp. 129-131 (cita en p. 131) y (2013), pp. 5-8, que ofrece comentarios muy jugosos a pesar de que — como confiesa - se centra en la tradición del anillo mágico y la fortuna de la obra (2010, p. 131, n. 4). Antes, Montesinos (1922), p. 151, apuntaba: «Sólo en La sortija del olvido, claramente posterior, puede verse una continuación de la historia del príncipe de Albania», una relación que comentaba en pp. 170-172.

${ }^{19}$ La relación entre los reinos de Hungría y Polonia se da en La corona de Hungría, con una guerra que los enfrenta. 
bien conmigo»; «yo te le mataré, / por el desdén que me has hecho», pp. 289-290). El rey le sorprende en este trance y le critica por ser «del estado subido / [...] indigno e incapaz» (p. 290), sin que todavía entonces el príncipe refrene su atrevimiento, cual «matasiete» (p. 290). La primera jornada termina con la sentencia del monarca, que aprueba los amores de Leonido y Rosilena al tiempo que ordena a su heredero que no salga de sus aposentos.

Este revés hace que el príncipe, en su encierro, determine fingir que ha perdido la razón y simula diferentes «temas» o 'locuras' (primero poseer dos cabezas, después ser invisible y principalmente negarse a comer) con la intención de causar lástima al rey y hacerle, así, cambiar de decisión. Mientras los personajes se preocupan, el público descubre pronto que se trata de una simulación gracias a los apartes del príncipe y su criado Fabio. El monarca, un tanto desesperado, piensa casarse él mismo con Rosilena para aquietar al príncipe y al infante (p. 323), y lo hiciera de no ser porque el conde se dice casado en secreto con ella, mintiendo para proteger los amores de su amigo el infante. Ya en la tercera jornada, tienen lugar dos sucesos clave: primero, Leonido se convierte en nuevo rey de Polonia a la muerte de su tío (pp. 336-337), y deja, por tanto, de estar en situación de inferioridad frente a su hermano; después, el príncipe se confiesa «[m]uy acosado» del «oficio de fingir» (p. 330) y revela la verdad a Rosilena, que simula quererle durante una visita de este a su alcoba («Que todo aquello fingí, / porque así te me entregasen / y contigo me casasen», p. 348), y esta a su vez revela la traza a su amado Leonido («es invención cuanto ha hecho», p. 352). Al final, puesto que el príncipe sigue simulando ante su hermano (pp. 357-358), Leonido dispone una cura para su mal: con la promesa de acatamiento del rey a las condiciones del remedio y con palabrerías de encantamientos de por medio, Leonido se casa con Rosilena delante del príncipe y logra además no romper la promesa inicial de no casarse en el suelo (p. 292) porque lo hace subido a «una silla sobre una parihuela» (acot. p. 362). En fin, el propio príncipe descubre sus mentiras («cuanto hice fingía, / porque atraerte quería, / señor, a mi voluntad», p. 364) y el rey finalmente declara un perdón general para todos.

El príncipe melancólico, por tanto, constituye el primer caso en el que Lope hace uso de la máscara de la locura fingida dentro de un contexto político, aunque esta se oriente claramente a fines amorosos ${ }^{20}$. Asimismo, el final feliz de la comedia no evita que el príncipe sea un ejemplo de mal gobernante, pues hace uso de esta simulación para fines no ya ilegítimos sino injustos, sin que justifique por un peligro mayor ni llegue a sacar lección alguna de esta traza.

Desde esta primera cala hasta El cuerdo loco Lope introduce algunas variantes significativas con las que delinea un drama mejor perfilado ${ }^{21}$. Primeramente,

${ }^{20}$ Sobre este recurso dramático, ver Sáez (2013 a).

${ }^{21}$ Para este caso, retoco algunas ideas explicadas en Sáez (2015), sobre la dinámica de 
desaparece la figura paterna (ha muerto) y el príncipe Antonio, si bien queda como la máxima representación del poder en Albania (que debe entenderse igualmente como Hungría), debe hacer frente a una conjura en su contra que comentaré dentro de un momento ${ }^{22}$. En segundo lugar, se desliga el conflicto amoroso de la órbita familiar para añadir un componente político apenas presente antes en la disputa fraterna por la sucesión al trono magiar: el príncipe ama a Lucinda y es correspondido, pero se aprovecha injustamente de su poder para favorecer sus amores, y no solo se atreve a entrar en la casa de su amada sin temer al dueño de la casa y su hermano, el conde Próspero, sino que lo destina a la guerra contra los turcos (vv. 105-124) para tener el campo libre en sus pretensiones amorosas, en un remedo de la historia bíblica del triángulo formado por el rey David, Urías y Betsabé (II Samuel, 2-27): de tal suerte, honra al personaje y queda, «en público y en secreto, / de su estorbo descuidado» (vv. 340-341).

Frente a la comedia precedente, la rivalidad esencialmente amorosa entre el príncipe y el infante deja paso a un conflicto político imbricado con las pasiones que unen a ciertos personajes, al tiempo que hace que la disputa salte a la esfera social debido al estatuto político de los mismos. Lope da así con la tecla de la traición orquestada por un noble (el duque Dinardo) y una dama cercana al gobernante (su madrastra Rosania), peligro que se afronta de nuevo con un ardid fingido que goza de mayor desarrollo que en El príncipe melancólico.

Para hacerse con el trono de Albania y tras descartar otras opciones de acabar con la vida de Antonio, Rosania aconseja «darle una bebida / con que se vuelva loco» y sea así declarado «inhábil para el cetro del gobierno» (vv. 681-683). Para ello, quieren sobornar al cocinero Roberto para que envenene la epitima ('pócima') que toma Antonio cada mañana contra su humor melancólico (vv. 693-695, y recuérdese la pasión que supuestamente aflige al príncipe de la comedia anterior) con ciertas sustancias que lo vuelvan loco (vv. 700-703). Sin embargo, el cocinero —que no por nada es español — revela la conspiración a Antonio (vv. 835-854) y, todavía más, le aconseja muy oportunamente que simule enloquecer por el veneno:
Bébele en mi confianza, fíngete loco, y entiende quién, cuándo y cómo te vende, que quien sufre, mucho alcanza. Y, cuando con gran secreto puedas venganza tomar,

disimulación y el género dramático de la comedia.

${ }^{22}$ El empleo de Albania se destina a evitar críticas de la censura, muy puntillosa en ciertas ocasiones en las que se menciona Bohemia o Francia, según se explica en el prólogo de la comedia (Sánchez Jiménez y Sáez, en prensa). Asimismo, en ello abunda el parentesco intertextual que vengo comentando. 
podrás a Albania mostrar

la salud de tu sujeto. (vv. 867-874)

Este fingimiento, que parte de un personaje de baja condición aunque su origen español le concede un aire superior, se revelará muy acertado porque le servirá como escudo efectivo contra el peligro que corre.

Así pues, Antonio comienza a hacerse pasar por loco desde el final de la primera jornada (v. 1003 y ss.) y para ello resulta esencial el discurso disparatado (vv. 12751324, entre otros pasajes), que a través del «decir sin decir» descubre un doble sentido que remite claramente a su situación, para confusión de los personajes e hilaridad del público ${ }^{23}$. De hecho, Antonio teme ser descubierto y determina dar mayores muestras de furor para permanecer a salvo, como afirma en un aparte: «Mucho hablo, por mi daño; / quiero fingirme más loco, / no caigan en el engaño» (vv. 1254-1256). Mientras tanto, los conspiradores quieren matar a Lucinda para culpar a Antonio y hacer que Próspero, que por entonces negocia con el sultán Bajá, regrese para vengarse (vv. 1231-1245). Pero el príncipe informa del plan a su amada y sigue liando la maraña: mata al traidor Leonido, hace creer que este ha asesinado a Lucinda, quien se fuga con el fiel Roberto. Finalmente, en la tercera jornada el ejército le devuelve a Antonio tanto la libertad como la autoridad y entra con un grupo de hombres enmascarados en palacio y restaura el orden alterado. Entonces, Dinardo no tiene más remedio que confesar que el príncipe es «el más cuerdo / que ha visto el mundo», pues ha "vencido la envidia y las traiciones / mayores que se han visto» (vv. 2962-2965).

En este caso, la locura simulada del príncipe se imbrica en la cuestión de la disimulación, una de las piedras de toque de los debates políticos coetáneos tras El príncipe (1513, pero publicado en 1531), ya que entre las diversas críticas que se destinan a las ideas de Maquiavelo, se admite el ejercicio de una dissimulatio legítima y honesta, que es aquella que se emplea de forma ocasional, por un tiempo limitado y solamente por motivos justos, como hace Antonio en esta comedia. El cuerdo loco puede leerse, por tanto, como una lección de ars gubernandi en un doble sentido, ya que se detiene tanto en el recto ejercicio del poder como, más especialmente, en las actuaciones que resultan legítimas en situaciones de amenaza.

Posteriormente, Lope vuelve sobre sí mismo en La sortija del olvido, comedia en la que no solo mantiene el ambiente húngaro sino que recupera de cerca el esquema de El cuerdo loco. En esencia, tres son los puntos en común: los preparativos de una traición entre un noble ambicioso y un pariente del rey, los

${ }^{23}$ Serralta (2004), pp. 174-175. Se relaciona con la «fantasía verbal» del loco festivo (Hermenegildo, 1995, pp. 14-15). 
amores mal encaminados del gobernante y el recurso de la locura fingida como estrategia de disimulación política ${ }^{24}$.

Las similitudes arrancan desde los primeros acordes de las comedias, que comparten dos secuencias muy cercanas, según ya señala López Martínez ${ }^{25}$ : el encuentro nocturno entre el monarca y su amada seguido de los preparativos de la traición se da la vuelta en La sortija del olvido para anteponer la escena política al lance amoroso. Así, la acción se abre con el diálogo entre el caballero Adriano y la infanta Arminda, hermana del rey Menandro, que conspiran para alzarse con el trono de Hungría. López Martínez precisa que en La sortija del olvido unifica Lope dos secuencias divididas en El cuerdo loco: «el convencimiento de la dama por parte del noble, y el diseño del plan para apartar al rey sin atentar contra su vida», para coincidir «nuevamente en la forma elegida por los traidores para atentar contra el rey, que es aprovechando el momento en que se viste por la mañana» ${ }^{26}$. Efectivamente, los conjurados primero determinan matar al monarca, pero descartan esta idea inicial por temor a matar a un familiar (vv. 30-32) - y no ya por una mejor alternativa-. El medio entonces elegido es en los dos casos volver loco al rey, que aquí se logrará mediante un anillo mágico que le dan siempre cuando el príncipe se lava y se viste por la mañana, escena seguramente grata — por familiar - al público cortesano.

Una variación importante respecto a la trama de El cuerdo loco es justamente que el encanto debe afectar solo a «la razón / y el discurso natural / por algún tiempo» (vv. 81-83), un resquicio que establece expresamente Arminda para seguir adelante (ver infra):

\author{
Si es tal \\ que en cualquier justa ocasión \\ le deja volver en sí, \\ licencia permitiré, \\ pero, si no, vengaré \\ su agravio y mi engaño en ti. (vv. 83-88)
}

Con ello, quieren lograr que esté «para la corona sin sentido» (v. 1915), como se dice después. Luego de que Adriano acepta esta condición (ver vv. 107-114), se desplaza la acción a Menandro, que sale de noche para ver a su amada Lisarda. Durante el galanteo, el poderoso vuelve a ser sorprendido por el padre de la dama, el duque Sinibaldo (vv. 301-366), pero si en este caso el rey no duda en revelar su

\footnotetext{
${ }^{24}$ Más sobre traiciones en el corpus de Lope se puede ver en Montesinos (1922), pp. 175185.

${ }^{25}$ López Martínez (2010; 2013), pp. 5-8.

${ }^{26}$ López Martínez (2013), p. 6. En otro lugar, advertía que la secuencia de La sortija «es una reelaboración de dos escenas de El cuerdo loco» (2010, p. 130).
} 
identidad, es para disculparse diciendo que simplemente «pasaba por aquí» (v. 325). Con todo, el barba queda receloso y determina alejar a su hija de la corte y de Menandro hasta que llegue su pretendiente, el conde Arnaldo (vv. 381-398). Entonces, el parecido del rey con el príncipe Antonio aumenta porque ambos hacen frente a la adversidad de forma pareja: en El cuerdo loco se manda a la guerra al hermano de la dama, mientras en La sortija del olvido se manda encarcelar al padre de la amada, con la diferencia añadida de que a Lisarda le espera otro marido que también se debe esquivar para lograr el buen fin de los amores.

A partir de ahí, acaban las similitudes y solo permanecen una serie de juegos con la locura o el encantamiento respectivo de los dos gobernantes, con la salvedad de que en La sortija del olvido el monarca pierde realmente la razón cuando porta el anillo y solamente en la tercera jornada descubre la verdad y puede fingirse loco para solucionar con gran cordura el conflicto. Nuevamente, es un personaje secundario quien ofrece la clave al poderoso: el gracioso Lirano sustituye al cocinero Roberto y descubre a Menandro la traza sufrida al tiempo que le propone cómo salir airoso del peligro ${ }^{27}$ :

Tú estabas para morir
de algún fiero encantamiento,
con que estabas olvidado
del discurso natural.
[...]
Y poniéndote en la mano
el anillo, es buen acuerdo
el fingirte loco.
(vv. 2555-2558, 2665-2667)

Así, con esta argucia («Déjame disimular», v. 2723; «el rey mude de semblante, fingiendo que está loco», v. 2724acot.) se vuelve a fingir trastornado y logra que sean los propios conspiradores quienes se condenen juzgando un caso supuesto. Por tanto, la máscara de la locura aparente goza de un alcance menor en la comedia, pues aparece únicamente en los últimos versos de la tercera jornada (hasta v. 2817). En este sentido, es notable el aprovechamiento del motivo del envenenamiento del rey, que adquiere un desarrollo novedoso de principio a fin: frente a su temprana aparición al final de la primera jornada de El cuerdo loco, en La sortija del olvido solamente entra en acción en la segunda (en v. 1187acot. Menandro se pone el anillo encantado por vez primera) porque Lope concede aquí mayor espacio a los preparativos de la conjura; sin embargo, en un alarde de concentración de acción dramática y recursos escénicos, la comedia «va a centrarse en las confusiones que

\footnotetext{
${ }^{27}$ Ya aprecia el parecido de esta escena López Martínez (2013), p. 8, porque «parece todavía recordar la estrategia dramática que configura la mayor parte de la obra anterior».
} 
crea en la corte el intermitente encantamiento del [r]ey, dando además mucha mayor importancia al elemento cómico de lo que tenían los equívocos del cuerdo loco Antonio», a decir de López Martínez ${ }^{28}$. Esta mayor dosis de sales cómicas es resultado de la estrategia empleada para tornar loco a Menandro, ya comentada: la sortija mágica hace que el rey pierda la memoria (vv. 1253-1254, 1538-1541 y 2302), pero sin ella vuelve en sí y en las dos ocasiones en que se la quita debe tratar de corregir cuerdo sus decisiones locas, un movimiento de ida y vuelta que configura el enredo y despierta la risa.

En suma, las tres comedias palatinas constituyen un buen ejemplo de la afición de Lope a regresar conscientemente sobre composiciones previas, en una cadena en la que añade a su vez ingredientes de piezas anteriores y posteriores. En esta reescritura encadenada destaca la imbricación de amor y poder a partir de El cuerdo loco y el empleo de la máscara fingida de la locura como estrategia legítima de disimulación política para defenderse de graves amenazas.

Más allá de este trío fuertemente enlazado, hay otra serie de elementos que reaparecen en la veintena de comedias húngaras de Lope y que revelan la existencia de un cierto patrón para su diseño. Así, el conflicto entre amor, poder y deber es una constante que da buenos réditos: por ejemplo, en Obras son amores (1613-1618; Parte XI, 1618) es el rey Felisardo quien se enamora de Laura, la dama de Lucindo, un caballero que le sirve y que se ve en la obligación de ayudar a su señor a cortejar a su amada hasta que el monarca les empareja en el final de la comedia. Del mismo modo, muchas comedias húngaras suelen abrir boca con lances propios de comedia urbana o del género de capa y espada, un incipit que - a más de los casos vistosse repite en La obediencia laureada y primer Carlos de Hungría (1605-1606; Parte VI, 1614), con el duelo inicial entre Alejandro y Filipo, o el espionaje por parte de Carlos del galanteo de Doristeo con su hermana ${ }^{29}$.

\section{Final}

En síntesis, desde la ladera intertextual se contempla el desarrollo de la comedia palatina en Lope, que a partir de un primer ensayo (en torno a 1590) reelabora la misma fórmula dramática en otras dos ocasiones, en un camino de ida y vuelta donde se busca la coherencia y la perfección, «el mejor aprovechamiento de los materiales» en acertada sentencia de Pedraza Jiménez ${ }^{30}$. Lope no mentía cuando defendía la fuerza de su ingenio natural, pero es igualmente cierto que no pocas de sus comedias nacen bajo el signo de la reescritura.

\footnotetext{
${ }^{28}$ López Martínez (2013), p. 14.

${ }^{29}$ Ver Usandizaga (2005), p. 298.

${ }^{30}$ Pedraza Jiménez (1998), p. 117.
} 


\section{Obras citadas}

ANTONUCCI, Fausta, «Reescritura e intertextualidad en El médico de su honra de Calderón», en La tragédie espagnole et son contexte européen (XVI ${ }^{e} X V I I^{e}$ siècles), ed. C. Couderc y H. Tropé, Paris, Presses Sorbonne Nouvelle, 2013, pp. 229-237.

Argente Del Castillo, Concepción, «Hungría en el teatro de Mira de Amescua», en La teatralización de la historia en el Siglo de Oro español. Actas del III Coloquio del Aula-Biblioteca «Mira de Amescua» celebrado en Granada del 5 al 7 de noviembre de 1999 y cuatro estudios clásicos sobre el tema, ed. Roberto Castilla Pérez y Miguel González Dengra, Granada, Universidad de Granada, 2001, pp. 83-100.

Bocsi, J. Peter, «Hungría en el teatro de Lope de Vega», Revista de Literatura, 31, 1967, pp. 95-103.

— «Hungría en el teatro de Lope de Vega», Segismundo, 11, 1975, pp. 49-60.

DEL Río PARRA, Elena, «Entre historia y relato: los orígenes de El animal de Hungría, de Lope de Vega», Hispanófila, 139, 2003, pp. 49-60.

FERnÁndez MosquerA, Santiago, «Reescritura en el Siglo de Oro: diferentes estrategias autoriales», en El siglo de Oro español: texto e imagen (Congreso Internacional, GRISO / Ermitage, San Petersburgo), ed. Ignacio Arellano y Vsévolod Bagnó, Pamplona, Eunsa, 2010, pp. 23-37.

GARCÍA-VARELA, Jesús, «El discurso bufonesco y La sortija del olvido de Lope de Vega», en Looking at the Comedia in the Year of the Quincentennial. Proceedings onf the 1992 Symposium on Golden Age drama (University of Texas, El Paso, March 18-21), ed. Barbara L. Mujica, Sharon D. Voros y Matthew D. Stroud, Lanham, University Press of America, 1993, pp. 195202.

GÓMEZ, Jesús, «Historia y ficción: La corona de Hungría», en La Dinastía de los Austrias: las relaciones entre la Monarquía católica y el Imperio, coord. José Martínez Millán y Rubén González Cuervo, Madrid, Polifemo, 2011, vol. 3, pp. 1947-1963.

- El modelo teatral del último Lope de Vega (1621-1635), Valladolid / Olmedo, Universidad de Valladolid / Ayuntamiento de Olmedo, 2013.

GONZÁLEZ CUERVA, Rubén, «"El prodigioso príncipe transilvano”: la larga guerra contra los turcos a través de las "relaciones de sucesos”», Studia historica, 28, 2006, pp. 277-299.

GUTIÉRREZ GIL, Alberto, «Hungría como espacio mítico en las comedias palatinas de Lope de Vega, Mira de Amescua y Rojas Zorilla», en Lope de Vega y el teatro clásico español: nuevas estrategias de conocimiento en humanidades, dir. Joan Oleza, Teatro de palabras: revista sobre teatro áureo, 7, 2013, pp. 217-235.

[Disponible: http://www.uqtr.ca/teatro/teapal/TeaPalNum07.html (Consulta: 09.12.2013).] 
HERMENEGILDO, Alfredo, Juegos dramáticos de la locura festiva: pastores, simples, bobos y graciosos del teatro clásico, Palma de Mallorca, Olañeta, 1995.

Herrero García, Miguel, Ideas de los españoles del siglo XVII, 2.a ed., Madrid, Gredos, 1966.

KORPÁS, Zoltán, «Húngaros en obras de Lope de Vega. Las fuentes históricas del drama El rey sin reino», Anuario Lope de Vega, 5, 1999, pp. 119-137.

LÓPEZ MARTíNEZ, José Enrique, «De sortijas antiguas y reyes encantados. Antecedentes literarios y fortuna de la comedia La sortija del olvido, de Lope de Vega», Nueva Revista de Filología Hispánica, 58.1, 2010, pp. 129-157.

Micó, José María, «Épica y reescritura en Lope de Vega», en Siglo de Oro y reescritura II: Poesía, ed. Marc Vitse, Criticón, 74, 1998, pp. 93-108.

MonTesinos, José F. (ed.), Lope de Vega Carpio, El cuerdo loco, Madrid, Centro de Estudios Históricos, 1922.

OLEZA, Joan, «La comedia y la tragedia palatinas: modalidades del arte nuevo», Edad de Oro, 16, 1997, pp. 235-251.

- «Reyes visibles, reyes temibles. El conflicto de la lujuria del déspota en el teatro de Lope de Vega», en «Por discreto y por amigo». Mélanges offerts à Jean Canavaggio, ed. Christophe Courderc y Benoît Pellistrandi, Madrid, Casa de Velázquez, 2005, pp. 305-318.

- «Variaciones del drama historial en Lope de Vega», Anuario Lope de Vega: texto, literatura, cultura, 19, 2013. 150-187. [En red.]

PEDRAZA JiMÉNEZ, Felipe B., «Algunos mecanismos y razones de la reescritura en Lope de Vega», en Siglo de Oro y reescritura II: Poesía, ed. M. Vitse, Criticón, 74, 1998, pp. 109-124.

RENNERT, Hugo A., «Lope de Vega's Los pleitos de Ingalaterra and La corona de Hungría», Modern Language Review, 13, 1918, pp. 455-464.

SÁEZ, Adrián J., «Locos y bobos: dos máscaras fingidas en el teatro de Lope de Vega (con un excurso calderoniano)», en Lope de Vega y la renovación literaria, coord. Antonio Sánchez Jiménez y Antonio Cortijo Ocaña, eHumanista, 24, 2013a, pp. 271-292.

— «Reescritura e intertextualidad en Calderón: No hay cosa como callar», Criticón, 117, 2013b, pp. 159-176.

- «Intrigas en la corte de Buda: disimulación política y género palatino en El cuerdo loco de Lope de Vega», Anuario Lope de Vega: texto, literatura, cultura, 21, 2015, pp. 95-115.

SAMBRIAN-TOMA, Oana, «Un producto del Arte nuevo: El rey sin reino de Lope y la imagen de Juan de Huniades», en El «Arte nuevo hacer comedias» en su contexto europeo. Congreso Internacional (Almagro, 28, 29 y 30 de enero de 2009), ed. F. B. Pedraza Jiménez, R. González Cañal y E. E. Marcello, Cuenca, Universidad de Castilla-La Mancha, 2010, pp. 195-206.

SÁnCHEZ JiMÉnEZ, Antonio, y Adrián J. SÁEZ (ed.), L. de Vega, El cuerdo loco, en 
Comedias de Lope de Vega. Parte XIV, coord. A. Blecua y J. E. López Martínez, Madrid, Gredos, en prensa.

SERRALTA, Frédéric, «Sobre disparate y comedia burlesca en el teatro de Lope», Criticón, 92, 2004, pp. 171-184.

TYLER, Richard W., «Otra mirada a dos comedias de Lope de Vega: La corona de Hungría y Los pleitos de Ingalaterra», Hispanófila, 18, 1963, pp. 21-75.

- (ed.), Lope de Vega Carpio, La corona de Hungría, Chapel Hill / Madrid, University of North Carolina / Castalia, 1972.

UsAndiZAGA, Guillem (ed.), Lope de Vega Carpio, La obediencia laureada y primer Carlos de Hungría, en Comedias de Lope de Vega. Parte VI, coord. Victoria Pineda y Gonzalo Pontón, Lleida, Milenio, 2005, vol. 1, pp. 293-450.

- La representación de la historia contemporánea en el teatro de Lope de Vega, Madrid / Frankfurt, Iberoamericana / Vervuert, 2014.

Vega Carpio, Lope de, Arte nuevo de hacer comedias, ed. E. Rodríguez Cuadros, Madrid, Castalia, 2011.

- La corona de Hungría, ed. Richard W. Tyler, Chapel Hill / Madrid, University of North Carolina / Castalia, 1972.

- El cuerdo loco, ed. Antonio Sánchez Jiménez y Adrián J. Sáez, en Comedias de Lope de Vega. Parte XIV, coord. José Enrique López Martínez, Madrid, Gredos, en prensa.

- La obediencia laureada y primer Carlos de Hungría, ed. Guillem Usandizaga, en Comedias de Lope de Vega. Parte VI, coord. Victoria Pineda y Gonzalo Pontón, Lleida, Milenio, 2005, vol. 1, pp. 293-450.

- Obras son amores, ed. Carlos Mota, en Comedias de Lope de Vega. Parte XI, coord. Laura Fernández y Gonzalo Pontón, Madrid, Gredos, 2012, vol. 1, pp. 611-758.

- El príncipe melancólico, en Comedias. III, ed. Jesús Gómez y Paloma Cuenca, Madrid, Fundación José Antonio de Castro, 1993, pp. 271-365.

- La sortija del olvido, ed. José Enrique López Martínez, en Comedias de Lope de Vega. Parte XII, coord. José Enrique Laplana, Madrid, Gredos, 2013, pp. 53364.

WARDROPPER, Bruce W., «"Work in Progress": The Poetic Creativity of three Seventeenth-Century Poets», Modern Language Notes, 105.2, 1990, pp. 180190.

WEBER DE KURLAT, Frida, «Hacia una sistematización de los tipos de comedias de Lope de Vega», en Actas del V Congreso Internacional de Hispanistas (Bourdeaux, 2-8 de septiembre de 1974), ed. Maxime Chevalier, Françoise Lopez, Joseph Perez y Noel Salomon, Bourdeaux, Instituto de Estudios Ibéricos e Iberoamericanos, 1977, vol. 2, pp. 867-871. 